\title{
ISRU Reactant, Fuel Cell Based Power Plant for Robotic and Human Mobile Exploration Applications
}

\author{
Russell S. Baird, Gerald Sanders, Thomas Simon, and Kerri McCurdy
}

Energy Systems Division, NASA Johnson Space Center, Houston Tx 77062, USA

(281) 483-9013, r.s.baird1@jsc.nasa.gov

\begin{abstract}
Three basic power generation system concepts are generally considered for lander, rover, and Extra-Vehicular Activity (EVA) assistant applications for robotic and human Moon and Mars exploration missions. The most common power system considered is the solar array and battery system. While relatively simple and successful, solar array/battery systems have some serious limitations for mobile applications. For typical rover applications, these limitations include relatively low total energy storage capabilities, daylight only operating times ( 6 to 8 hours on Mars), relatively short operating lives depending on the operating environment, and rover/lander size and surface use constraints. Radioisotope power systems are being reconsidered for long-range science missions. Unfortunately, the high cost, political controversy, and launch difficulties that are associated with nuclear-based power systems suggests that the use of radioisotope powered landers, rovers, and EVA assistants will be limited. The third power system concept now being considered are fuel cell based systems. Fuel cell power systems overcome many of the performance and surface exploration limitations of solar array/battery power systems and the prohibitive cost and other difficulties associated with nuclear power systems for mobile applications. In an effort to better understand the capabilities and limitations of fuel cell power systems for Moon and Mars exploration applications, NASA is investigating the use of In-Situ Resource Utilization (ISRU) produced reactant, fuel cell based power plants to power robotic outpost rovers, science equipment, and future human spacecraft, surface-excursion rovers, and EVA assistant rovers. This paper will briefly compare the capabilities and limitations of fuel cell power systems relative to solar array/battery and nuclear systems, discuss the unique and enhanced missions that fuel cell power systems enable, and discuss the common technology and system attributes possible for robotic and human exploration to maximize scientific return and minimize cost and risk to both. Progress made to date at the Johnson Space Center on an ISRU producible reactant, Proton Exchange Membrane (PEM) fuel cell based power plant project to demonstrate the concept in conjunction with rover applications will be presented in detail.
\end{abstract}




\title{
ISRU Reactant, Fuel Cell Based Power Plant for Robotic and Human Mobile Exploration Applications
}

\author{
Russell S. Baird, Gerald Sanders, Thomas Simon, Kerri McCurdy \\ Energy Systems Division, NASA Johnson Space Center, Houston Tx 77062, USA \\ (281) 483-9013, r.s.baird1@jsc.nasa.gov
}

\begin{abstract}
Three basic power generation system concepts are generally considered for lander, rover, and Extra-Vehicular Activity (EVA) assistant applications for robotic and human Moon and Mars exploration missions. The most common power system considered is the solar array and battery system. While relatively simple and successful, solar array/battery systems have some serious limitations for mobile applications. For typical rover applications, these limitations include relatively low total energy storage capabilities, daylight only operating times (6 to 8 hours on Mars), relatively short operating lives depending on the operating environment, and rover/lander size and surface use constraints. Radioisotope power systems are being reconsidered for long-range science missions. Unfortunately, the high cost, political controversy, and launch difficulties that are associated with nuclear-based power systems suggests that the use of radioisotope powered landers, rovers, and EVA assistants will be limited. The third power system concept now being considered are fuel cell based systems. Fuel cell power systems overcome many of the performance and surface exploration limitations of solar array/battery power systems and the prohibitive cost and other difficulties associated with nuclear power systems for mobile applications. In an effort to better understand the capabilities and limitations of fuel cell power systems for Moon and Mars exploration applications, NASA is investigating the use of In-Situ Resource Utilization (ISRU) produced reactant, fuel cell based power plants to power robotic outpost rovers, science equipment, and future human spacecraft, surface-excursion rovers, and EVA assistant rovers. This paper will briefly compare the capabilities and limitations of fuel cell power systems relative to solar array/battery and nuclear systems, discuss the unique and enhanced missions that fuel cell power systems enable, and discuss the common technology and system attributes possible for robotic and human exploration to maximize scientific return and minimize cost and risk to both. Progress made to date at the Johnson Space Center on an ISRU producible reactant, Proton Exchange Membrane (PEM) fuel cell based power plant project to demonstrate the concept in conjunction with rover applications will be presented in detail.
\end{abstract}

\section{THE NEED FOR ROVERS AND MOBILE PLATFORMS}

The mission enhancing benefits of rovers and Extra-Vehicular Activity (EVA) assistants have been demonstrated on the surface of both the moon and Mars. Apollo 14 utilized a $9 \mathrm{~kg}$, two-wheeled cart called the Modularized Equipment Transporter (MET) to carry EVA tools, and Apollo 15, 16, and 17 incorporated the Lunar Roving Vehicle (LRV) to significantly extend the range of astronaut scientific exploration of the lunar surface (Portree, 1997). Also, the robotic Russian Lunokhod 1 and 2 lunar rovers and later the U.S. Mars Pathfinder Sojourner rover demonstrated the versatility and scientific benefits of having a mobile science platform.

Based on the success and limitations of the Sojourner rover, NASA is designing and building larger and more capable rovers for future Mars exploration missions. In 2003, two Mars Exploration Rovers (MERs) will be launched separately with the capability of traveling up to 100 meters per day for 90 Mars days (sols) (JPL Exploration website). As early as 2009 , a long-range nuclear powered rover may also be launched to allow long duration surface exploration. Because of the experience gained with the MET and LRVs during the Apollo program, human missions beyond Low Earth Orbit (LEO) will likely utilize human transport rovers for long distance exploration, EVA assistant rovers for site exploration, and telerobotic rovers for potentially hazardous operations or to scout potential sites for future EVAs.

\section{ROVER POWER PLANT OPTIONS}

Four basic power storage and generation system concepts are generally considered for rover applications; batteries, solar arrays combined with batteries, radioisotope power units, and fuel cells. Each option has its benefits and 
weaknesses. A number of factors must be considered when selecting the appropriate power system for any particular mobile application, such as: cost, weight, volume, total and peak power requirements, operation environment, and mission duration.

\section{Battery}

Using batteries by themselves is the simplest, and potentially the lowest cost power storage and generation option. Battery energy densities as high as $125 \mathrm{~W} * \mathrm{hr} / \mathrm{kg}$ for Li-ion are possible, which can be translated into small power system masses. The Apollo LRV used two 36-volt silver-zinc batteries enabling a $62.4 \mathrm{~km}$ mission excursion capability (Portree, 1997). However, batteries on their own require a separate power generation system to recharge them if the total mission duration exceeds the battery system capability. Recharge time can be significant and may not be practical for typical mission operating timeframes.

\section{Solar Array with Batteries}

The most common power system considered for small-scale robotic mobile applications is the solar array and battery system. Both the Lunokhod and Sojourner rovers used solar arrays as the primary power source with batteries for nighttime power or as backup (NSSDC website). While relatively simple and successful, solar array/battery systems have some serious limitations for mobile applications. For typical rover applications, these limitations include relatively low total energy storage capabilities, daylight only operating times (6 to 8 hours on Mars or 14 of 28 days on the Moon), relatively short operating lives depending on the operating environment, rover/lander size limitations, and top-surface use constraints. Also, because low temperature environments can significantly impact battery efficiency and life, supplemental radioisotope heat sources may be required to protect the batteries and other critical hardware on the rover, as was the case for both the Lunokhod and Sojourner rovers.

\section{Nuclear Radioisotope}

Radioisotope-based power systems are being reconsidered for long-range science missions, such as the Mars exploration rover scheduled for launch in 2009. Radioisotope Thermoelectric Generators (RTG's) can provide long-term continuous power at up to a $7 \%$ thermal to electrical conversion efficiency. Dynamic isotope power systems (using Brayton or Stirling cycles) can provide continuous power at $\sim 20 \%$ efficiency (Wetch, 1990). Unfortunately, the high cost, relatively large system mass, political controversy, and launch difficulties that are associated with nuclear-based power systems suggests that the use of radioisotope powered landers, rovers, and EVA assistants will be limited.

\section{Fuel Cell}

The fourth power system concept now being considered for mobile applications is a fuel cell based power system. Fuel cell power systems can have the same or significantly better energy densities as batteries, and like radioisotope systems, fuel cells can provide continuous power for extended periods. Fuel cell power systems overcome many of the performance and surface exploration limitations of solar array/battery power systems and the prohibitive cost and other difficulties associated with nuclear power systems for multiple mobile applications. Like battery systems, fuel cells must be "recharged" with new fuel cell reactants, and require a separate power source to regenerate new fuel cell reactants. However, resupplying fuel cell reactants is not as time consuming as recharging batteries, and producing new fuel cell reactants can be done offline and in parallel with mobile exploration applications.

\section{IN-SITU RESOURCE UTILIZATION REACTANT USE IMPLICATIONS}

Technologies that will enable future human and human precursor missions to "live off the land" by using in-situ indigenous resources are being developed under the collective heading of In-Situ Resource Utilization (ISRU) 
technologies. These ISRU technologies will be used in the production of mission critical consumables, such as rocket fuels, oxygen, water, and gases for life support, EVA, and science applications using resources available at the base or exploration site. Human missions will require large quantities of these consumables. For example, even with a $100 \%$ closed loop life support system, extensive lunar or Mars planetary surface exploration by EVA is not possible without in-situ production of oxygen. Possible fuel cell reactant fuels, such as hydrogen, methane, and methanol are produced as by-products of many ISRU processes. It has been determined that the oxygen/fuel production rate to support a small Mars sample return mission that incorporates ISRU is similar to the rate needed to meet any of the following: reactant needs for a $600 \mathrm{~W}$ fuel cell powered rover, $\mathrm{O}_{2}$ production for daily surface EVAs, or backup $\mathrm{O}_{2}$ production for habitat life support. Therefore, a single small ISRU plant design can support multiple mission applications. Since this plant is approximately $1 / 10$ the size of the plant needed to support a human Mars ascent vehicle or long-range human rover, early demonstration of this smaller scale concept would reduce the risk to the later larger scale missions that rely on ISRU produced propellants. This would also allow for a smooth evolutionary architecture transition from robotic precursor missions to accessible surface exploration to sustainable surface exploration.

When examining all the elements required for accessible and sustainable robotic and human planetary surface exploration (habitats, rovers, landers, hoppers, EVA suits, etc.), a common-fluid surface infrastructure is possible when fuel cell power and ISRU are considered. This infrastructure would utilize $\mathrm{O}_{2}$ and fuel from a common ISRU supplied depot for (a) habitat and EVA life support, (b) long range rover, EVA assistant, and EVA suit fuel cell power, and (c) lander, hopper, and Unmanned Aerial Vehicle (UAV) propulsion. During an EVA, the astronaut could utilize consumables from the long-range rover or EVA assistant to extend operations or, in the event of an emergency, increase the chances of survival. This infrastructure would also minimize development and mission cost and risk since common core technologies and subsystems could be developed that support multiple applications for multiple destinations.

The same infrastructure concept also applies to the science surface exploration concept of "Robotic Outposts", where multiple rovers perform comprehensive exploration of a particular site of interest. In this case, a single ISRU plant (using solar arrays or nuclear isotope based power) would provide fuel cell reactants to multiple rovers. Each rover would have around-the-clock operation capability, high power for science instruments when needed, and no top surface constraints for placement of science instruments and cargo. The concept would also be relatively low cost and support long duration surface exploration since only a single, large, non-mobile power source is required. In short, ISRU in conjunction with fuel cell power systems have an extraordinarily attractive potential for mobile exploration applications for both robotic and human scale missions.

\section{ISRU SUPPLIED, FUEL CELL POWERED ROVER DEMONSTRATION}

In an effort to better understand the capabilities and limitations of fuel cell power systems for Moon and Mars exploration applications, the NASA Johnson Space Center (JSC) is investigating the use of ISRU produced reactant, fuel cell based power plants to power robotic outpost rovers, science equipment, and future human spacecraft, surface-excursion rovers, and EVA assistant rovers. The initial JSC efforts are in the form of a system level demonstration program.

\section{Project Scope}

The overall objective of this program is to characterize and demonstrate the feasibility of powering a planetary surface rover with a fuel cell based power plant using ISRU producible reactants. To do this, the program was broken up into three distinct phases that incrementally increase the technical difficulty addressed. The first phase uses off the shelf oxygen and hydrogen fuel cell and reactant storage technologies to work out the basic layouts, control scenarios, safety issues, and integration configurations of a mobile power plant. This initial phase of the program is called the ISRU Hydrogen/Oxygen Power Plant (IHOPP) project. Later phases of the program will use oxygen and methane reactants and address methane reformer issues (phase 2) and the cryogenic storage of the reactants (phase 3). The EVA Robotic Assistant (ERA), the modern equivalent of the Apollo MET currently being 
developed at JSC, was selected as the mobile demonstration testbed for the power plant. The remainder of this paper will discuss the details of the IHOPP portion of the program.

\section{Project Requirements}

The IHOPP project design requirements were primarily focused on the IHOPP to ERA interface. The ERA originally required an average power of $600 \mathrm{~W}$ for at least 6 hours and a peak power of at least $800 \mathrm{~W}$. This was a significant increase in ERA capabilities from earlier versions and was driven by the planned upsizing of the ERA rover testbed. The power quality requirement was defined to be 20 to $36 \mathrm{Vdc}$ with a maximum current of $80 \mathrm{~A}$ with voltage regulation to be provided by the rover end user, if needed. The maximum physical envelope of the IHOPP was defined to be $76.2 \mathrm{~cm}$ (30 in) [width] by $96.5 \mathrm{~cm}$ (38 in) [length] by $61 \mathrm{~cm}$ ( 24 in) [height] to fit within the ERA structural frame. Later ERA design changes drove the peak power requirement higher and the volume requirement lower. The power and data connectors were provided by the ERA. The practicalities of fuel cell operations and the external environment defined the IHOPP heat rejection requirements to be at least $430 \mathrm{~W}$ between the worst-case ambient temperature $\left(49^{\circ} \mathrm{C}\right)$ and the operating temperature of the fuel cell $\left(65^{\circ} \mathrm{C}\right)$. NASA pressure system (JHB 1710.13B) and oxygen/hydrogen safety (NSS 1740.15 and .16) standards were also used.

\section{Hardware Design}

There were three primary areas within the IHOPP that drove the overall design configuration of the system: reactant storage and distribution, fuel cell, and control systems (Figures 1 and 2). Each is discussed below:

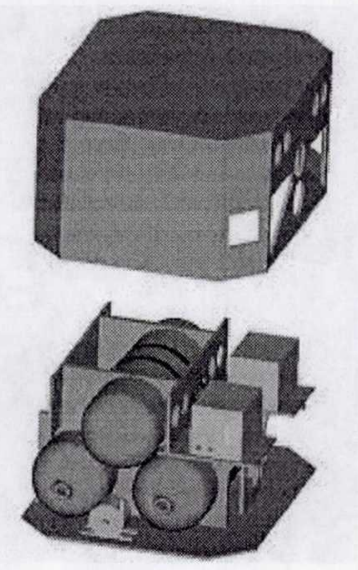

FIGURE 1. IHOPP Layout.

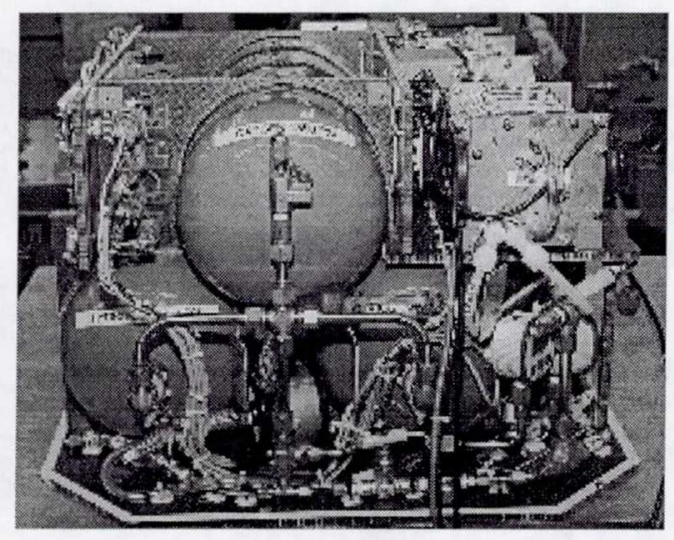

FIGURE 2. IHOPP Hardware in Buildup.

The reactant storage and distribution portion of the IHOPP consists of the reactant storage tanks, various isolation and relief valves, and a primary pressure regulator and pressure controller for each reactant. Three, 24.6L, carbon/epoxy overwrapped aluminum liner tanks with a thin outer fiberglass wrap for added external abrasion protection were selected for reactant storage. Two tanks are used for hydrogen storage and one is used for oxygen storage. Each tank can be pressurized up to $12755 \mathrm{kPa}$ (1850 psig) to stay within the ground system, "stand next to it" 4 to 1 pressure margin dictated by NASA standards. The isolation valves and the primary feed pressure regulators used are standard off-the-shelf hardware for high-pressure hydrogen and oxygen service and are physically close coupled to minimize the flow volume that is exposed to the high pressure. The system pressure is dropped to $689.5 \mathrm{kPa}(100 \mathrm{psig})$ downstream of the pressure regulator and is then dropped further to 62 or $68.9 \mathrm{kPa}$ (9 psig or 10 psig) for hydrogen and oxygen respectively by the pressure controller to control flow into each fuel cell. The pressure controller uses a proportional solenoid valve to maintain a constant pressure to the fuel cell stacks based on a pressure measurement located between the pressure controller and the reactant ejector. In all cases, the volume, mass, and cost were significant drivers in the selection of the fluid system hardware. 
Several fuel cell options were considered. A single, 800W average power Proton Exchange Membrane (PEM) fuel cell unit was selected for the original power requirement. Increases in the ERA power requirement over the course of the project led to the procurement of two such fuel cell units. Each fuel cell unit contains 34 cell membranes separated by graphite plates, all between two metal endplates held together in compression by tie rods. The two fuel cells are plumbed and electrically connected together in parallel. Forced convection air-cooling driven by fuel cell mounted fans and a pump circulated water-cooling system actively cool each fuel cell. The unused oxygen and product water generated by the fuel cell are collected in a tank where the liquid water is separated from the gas and collected. Saturated oxygen is then recycled back into the fuel cell for consumption. The hydrogen side of the fuel cell is dead-ended and requires occasional purging to remove excess water buildup. A small 12 Volt battery is also included in the design for short-term startup and shutdown load demands and to ensure power to the control system in the event that the fuel cells are shut down. The fuel cells recharge this $12 \mathrm{Vdc}$ battery during fuel cell operations.

The control system selected is a Programmable Logic Controller (PLC). The PLC was selected because of its simplicity, ruggedness, ease of programming, and smallness of mass and volume. The controller function for this design was intentionally kept as simple as possible. It collects limited system pressure and temperature data, monitors system operations, and controls various aspects of system operations against preset critical control limits for each phase of IHOPP operations. These control system operations range from the basic direction of the pressure controller operations feeding each fuel cell with reactants to system startup and shutdown transient control. The ladder logic programming used in the PLC proved to be ideal for the simple and repetitive nature of the system operations. PLC programming was accomplished by direct input into the PLC through an external laptop computer interface. System operating data can be transmitted real-time to the ERA or to an external laptop computer for later review.

In the end, the final design of the IHOPP met or surpassed the original requirements for the system. The system can provide the $600 \mathrm{~W}$ average power for in excess of 13 hours and up to $1600 \mathrm{~W}$ in peak power generally within the power quality requirements. The maximum power demonstrated during the stand-alone checkout testing was $1365 \mathrm{~W}$; although, the output voltage did drop below $20 \mathrm{Vdc}$ for loads above $60 \mathrm{~A}$. The maximum physical envelope of the IHOPP is smaller than the original requirements, measuring $70.5 \mathrm{~cm}(27.75 \mathrm{in})$ [width] by $86.4 \mathrm{~cm}$ ( $34 \mathrm{in}$ ) [length] by $43.7 \mathrm{~cm}(17.2 \mathrm{in})$ [height] even with the additional volume required for the reactant storage.

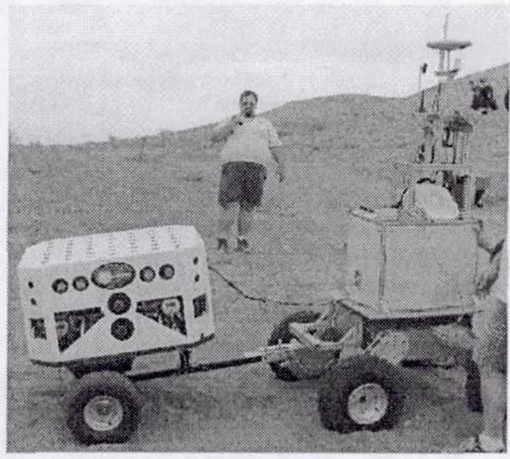

FIGURE 3. Combined IHOPP / Old ERA Operations.

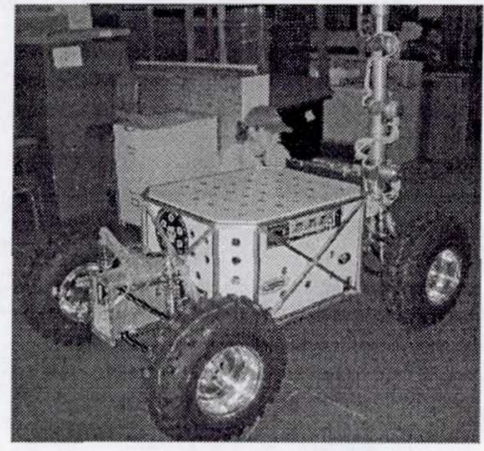

FIGURE 4. Combined IHOPP / New ERA Operations.

\section{Project Status and Plans}

The IHOPP design, fabrication, initial stand alone checkout testing at JSC, and field-testing in the Arizona desert with the ERA have been completed. During the desert field-testing, the IHOPP successfully powered both the old and new design ERA units (Figures 3 and 4). The IHOPP will undergo extensive post field-testing operations review at JSC. Upgrades and design adjustments will be implemented as needed based on the field-test performance to support integrated operations with the ERA early in 2003. The IHOPP will then be upgraded to use gaseous methane and oxygen reactants for the second phase of the program. This second phase of the program is tentatively called the ISRU Methane/Oxygen Power Plant (IMOPP) project and could start as early as late 2003. 


\title{
CONCLUSIONS
}

Overall, the IHOPP project has been a success. The performance of its design has surpassed the original requirements for the system. The IHOPP project has demonstrated that ISRU producible reactants can be profitably used in mobile fuel cell based power systems to support planetary surface rover applications. The IHOPP project is just the initial phase of a multi-phase JSC program to more fully explore the characteristics and limitations of mobile fuel cell power systems and ISRUs role with it. Later phases of the program will investigate the use oxygen and methane reactants and address methane reformer issues (phase 2) and the cryogenic storage of the reactants (phase 3 ).

\section{NOMENCLATURE}

\author{
ERA EVA Robotic Assistant \\ EVA Extravehicular Activity \\ IHOPP ISRU Hydrogen/Oxygen Power Plant \\ IMOPP ISRU Methane/Oxygen Power Plant \\ ISRU In-Situ Resource Utilization \\ JSC Lyndon B. Johnson Space Center (NASA) \\ JPL Jet Propulsion Laboratory (NASA) \\ LEO Low Earth Orbit \\ LRV Lunar Roving Vehicle \\ MER Mars Exploration Rover \\ MET Modularized Equipment Transporter \\ NASA National Aeronautics and Space Administration \\ NSSDC National Space Science Data Center \\ PEM Proton Exchange Membrane (fuel cell) \\ PLC Programmable Logic Controller \\ RTG Radioisotope Thermal Generator \\ UAV Unmanned Aerial Vehicle
}

\section{REFERENCES}

JHB 1710.13B, "Design, Inspection, and Certification of Pressure Vessels and Pressurized Systems," NASA, Johnson Space Center, March 1994

JPL Mars Exploration Website (http://mars.jpl.nasa.gov/missions/future/2003.html)

National Space Science Data Center (NSSDC) website (http://nssdc.gsfc.nasa.gov). NSSDC ID: 1973-001A and MESURPR

NSS 1740.15, "Safety Standard for Oxygen and Oxygen Systems," NASA Headquarters, January 1996

NSS 1740.16, "Safety Standard for Hydrogen and Hydrogen Systems," NASA Headquarters, January 1996

Portree, D. S. F., and Trevino, R. C., "Walking to Olympus: An EVA Chronology," Monographs in Aerospace History Series \#7, Oct. 1997

Wetch, J., History of Space Nuclear Power Short Course Notes, $77^{\text {th }}$ Symposium on Space Nuclear Power, Albuquerque, NM, Jan. 6, 1990 